\title{
The role of the transbranchial potential difference in hyperosmotic regulation of the shore crab Carcinus maenas
}

\author{
Andreas Winkler \\ Biologische Anstalt Helgoland (Zentrale); Notkestraße 31, D-2000 Hamburg 52, \\ Federal Republic of Germany
}

\begin{abstract}
When isolated gills of the shore crab Carcinus maenas were bathed and perfused with identical solutions on both sides ( $50 \%$ sea water), a spontaneous transepithelial potential difference (PD) of some millivolts (hemolymph side negative) was established. This PD is of active nature and requires the metabolism of the living cell, since it uses its own sources of energy in addition to organic nutrients offered in the flow of artificial hemolymph. Addition of sodium cyanide and dinitrophenole to bathing and perfusion medium resulted in reversible breakdown of PDs in a concentration-dependent mode. In posterior gills of $C$. maenas, the potential differences were more negative compared to data measured in anterior gills of the same individuals. These results are correlated with higher specific activities of Na-K-ATPase in posterior gills. Experiments with triamterene indicate that sodium uptake in $C$. maenas is sensitive to this diuretic drug, when applied on the apical side of the epithelial cell. The results obtained show that active uptake of sodium from medium to blood across the gills is performed by a complex mechanism including participation of several basal and apical transport steps.
\end{abstract}

\section{INTRODUCTION}

Marine invertebrates successfully inhabiting brackish water environments or tidal estuaries with changing salinities have acquired the capacity to hyperregulate their body fluids with respect to the ambient medium. In hyperregulating crustaceans, permanently proceeding passive losses of salts are compensated for by active absorption of ions, mainly $\mathrm{Na}^{+}$and $\mathrm{Cl}^{-}$, occurring essentially through epithelial cells of the gills.

During recent years, numerous investigations were concerned with the role of the Na-K-ATPase in hyperregulating aquatic animals (reviewed by Towle, 1981; 1984 a, b). It is a well established fact that enhancement in branchial Na-K-ATPase activity occurs when the animals are acclimated to low salinities. Therefore, most of these studies were engaged with enzymatic investigations in gill homogenates or in various fractions and membrane vesicles of epithelial cells in combination with analyses of ionic constituents of body fluids.

In the chinese crab Eriocheir sinensis, Koch et al. (1954) demonstrated that $\mathrm{Na}^{+}$ions were taken up from the external medium by isolated gills. Péqueux \& Gilles $(1978,1981)$, measuring the $\mathrm{Na}^{+}$influx in isolated perfused gills of $E$. sinensis, concluded that in freshwater-acclimated animals the active uptake of $\mathrm{Na}^{+}$, which counterbalanced salt 
losses along the concentration gradient, was mostly achieved across the three posterior pairs of the gills. Conversely, the $\mathrm{Na}^{+}$fluxes measured in the three anterior gill pairs seemed to be passive. In general, these ion-transporting mechanisms were closely correlated with the appearance of electrical currents and potential differences across the ion-transporting gill epithelium.

Besides being suitable for investigations of enzyme activities, isolated perfused gill preparations represent a further method for studying the mechanisms of hyperregulation. In this context, Siebers et al. (1985) have shown that the Na-K-ATPase generates a transepithelial potential difference (PD) between external medium and blood in the hyperregulating shore crab Carcinus maenas. The advantage of this method is that the potential difference between blood and medium is stable during several hours of the experiments. The stability of PD enabled the analysis of the influences of sodium and potassium on the transepithelial potential differences. By applying $\mathrm{K}$ and ouabain independently on both surfaces of the epithelial cells, it was demonstrated that the PD generating Na-pump is located at the basolateral side.

In the present paper, experimental evidence is given to show that the potential difference generated in the gill of $C$. maenas is of active nature. The difference in $\mathrm{Na}-\mathrm{K}$ ATPase activities in anterior and posterior gills of the crab is also reflected in different magnitudes of potential differences in gill 4 (anterior) and gill 8 (posterior) of $C$. maenas. Experiments concerning the effects of the diuretic drug triamterene on the transbranchial potential difference were performed in order to obtain information about sodium entry on the apical membrane of epithelial cells.

\section{MATERIALS AND METHODS}

\section{Crabs}

Male and female specimens of Carcinus maenas (L.) were collected in autumn 1984 and summer 1985 by a fisherman at the Kiel Fjord, western Baltic Sea. The crabs were kept in the laboratory at $18{ }^{\circ} \mathrm{C}$ in $200-\mathrm{l}$ tanks containing natural sea water diluted down to $10 \% \mathrm{~S}$ with demineralized water. The brackish water was permanently aerated and gravel-filtered. The density was 8-10 shore crabs per aquarium and short daylight periods of $6 \mathrm{~h}$ were chosen in order to avoid moulting. For the experiments, only crabs with a minimum carapace width of $50 \mathrm{~mm}$ (fresh weights of the individuals between 40 and $60 \mathrm{~g}$ ) were used. The crabs were fed three times a week with pieces of bovine heart, but starved two days prior to experimental use.

For investigations of whole body potentials, shore crabs were acclimated to sea water and brackish waters of different salinities. Minimum acclimation time was one month for all experiments.

\section{Whole body potentials}

Whole body potentials of Carcinus maenas were measured by means of two reference electrodes $(\mathrm{Ag} / \mathrm{AgCl}$, Ingold, Frankfurt/Main, inserted in glass vessels containing $3 \mathrm{M} \mathrm{KCl}$, which were in contact with hemolymph and external media via agar bridges $(3 \%$ agar in $3 \mathrm{M} \mathrm{KCl})$. The crabs were fixed by hand in the acclimation brackish and sea 
water. Only the dorsal surface of the carapace emerged out off the water. The contact to the hemolymph was established by drilling a thin hole into the cardial region of the carapace and inserting a special agar bridge directly into the pericardial space. Potential differences between whole crabs and external media were measured with a digital multimeter (MX 562, Metrix, France).

\section{Potential differences of isolated perfused gills}

The technique of perfusing isolated gills of Carcinus maenas was applied according to Siebers et al. (1985). Measurements of potential differences were performed by means of two electrodes ( $\mathrm{Ag} / \mathrm{AgCl}$ in $3 \mathrm{M} \mathrm{KCl}$, Ingold Frankfurt/Main) connected with the internal and external medium via agar bridges ( $3 \%$ agar in $3 \mathrm{M} \mathrm{KCL}$ ). By definition the reference electrode was inserted into the external medium. Potential differences were measured with a millivoltmeter (Selectlon 5000, Beckman, München). The gills were bathed and perfused with natural sea water diluted by $50 \%$ with distilled water. The resulting sodium concentration was $200 \mathrm{mM} \mathrm{Na}=445 \mathrm{mOsm} \mathrm{kg}^{-1}$ (Winkler et al., 1982). By using symmetrical solutions on both sides, the establishment of diffusional (passive) potentials was avoided. Before experimental use the diluted sea water was stored in a glass aquarium at $18^{\circ} \mathrm{C}$ permanently aerated and gravel-filtered. Perfusion experiments were performed in the laboratory at room temperature.

For experiments testing the influence of added nutrients on establishment of the potential difference, artificial nutrients were dissolved in $50 \%$ sea water according to Siebers et al. (1972). The final concentrations were $(\mathrm{mM}): \mathrm{NH}_{4} \mathrm{Cl} 100$, glucose 100, glycine 30 , proline 20 , taurine 20 , lysine 20 . Nutrient mixtures were stored deep-frozen at $-25^{\circ} \mathrm{C}$.

All chemicals were purchased from Merck (Darmstadt), except for the amino acids, which were purchased from Sigma (München) and 2,4-dinitrophenole from Serva (Heidelberg). Triamterene was obtained from Sigma (München).

\section{RESULTS}

\section{Whole body potentials}

The results of measurements of potential differences between whole crabs and the external acclimation media are shown in Figure 1. Data of whole body potentials were negative. Means amounted to about $-3 \mathrm{mV}$, and were not susceptible to changes of ambient salinity. Strongly hyperregulating shore crabs in $10 \% \mathrm{~S}$ exhibited about the same potential difference $(-3.3 \pm 1.3 \mathrm{mV})$ as specimens from $33 \% \mathrm{~S}(-2.6 \pm 1.3 \mathrm{mV})$, the latter exhibiting passive ion distributions between hemolymph and external medium.

\section{Potential differences across isolated perfused anterior and posterior gills}

The following experiments were performed with isolated gills. In order to avoid diffusional potentials, bathing and perfusion salines were identical. $50 \%$ natural sea water was applied as external and internal medium. Under these conditions, the estab- 


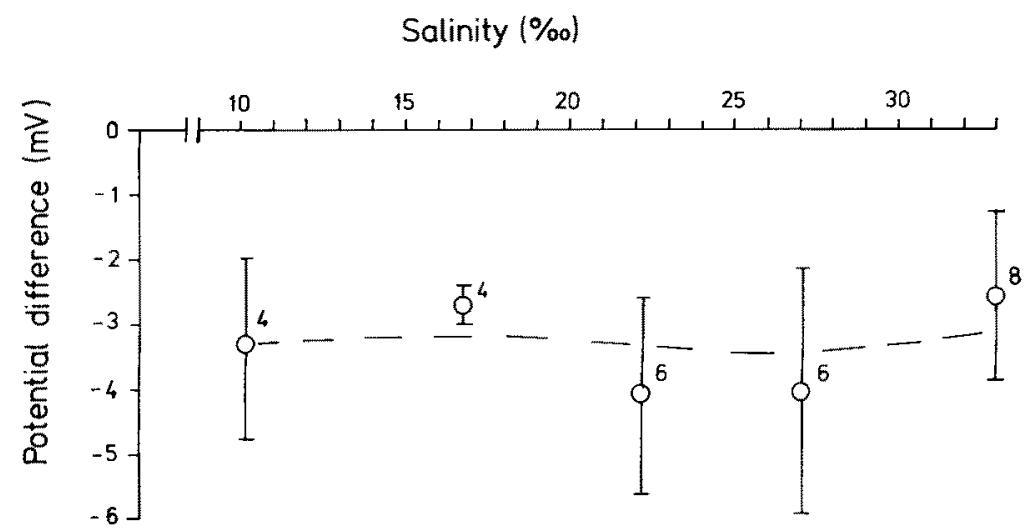

Fig. 1. Carcinus maenas. Potential differences between whole crabs and external media in relation to acclimation salinity. Data represent means, vertical bars standard deviations, obtained from a number of individuals indicated in the graph

lishment of spontaneous potential differences was observed. Transepithelial PDs were relatively stable over time. The hemolymph (internal) side was negative in comparison to the apical (external) side. In posterior gills (8) of crabs acclimated to $10 \% \mathrm{~S}$ the potential differences were significantly more negative (mean $-2.8 \mathrm{mV}$ ) when compared to data measured in anterior gills (4) of the same individuals (mean $-0.8 \mathrm{mV}$ ) (Fig. 2).

\section{Time $(\min )$}

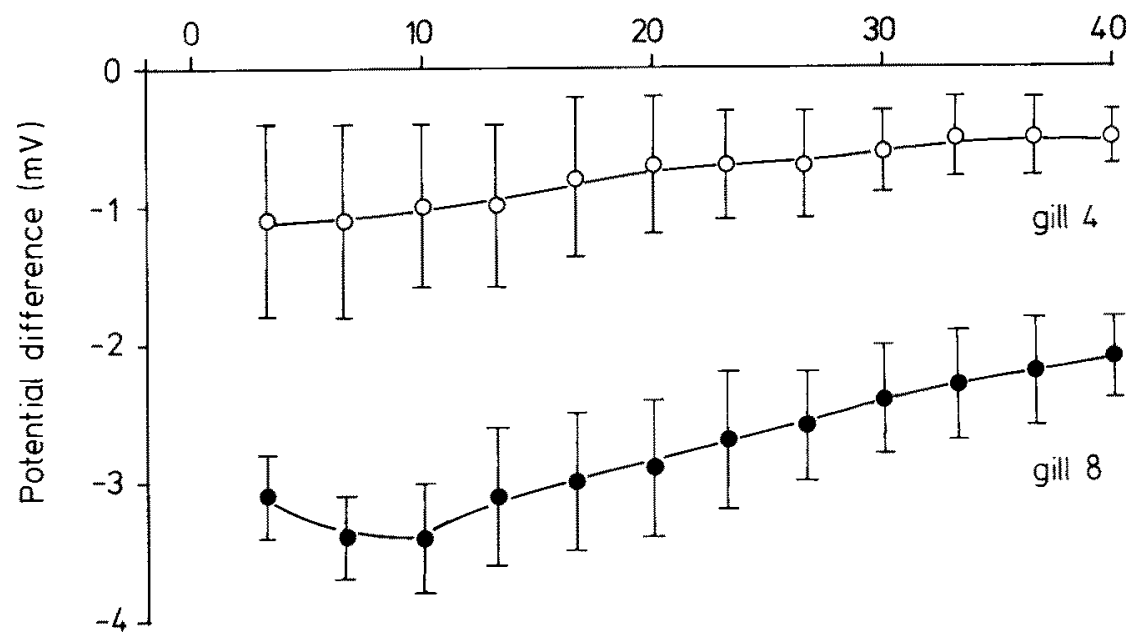

Fig. 2. Carcinus maenas. Comparison of the potential differences across isolated perfused gill 4 (open circles) and gill 8 (closed circles) of crabs acclimated to brackish water of $10 \% \mathrm{~S}$. The gills were bathed and perfused with $50 \%$ sea water $\left(200 \mathrm{mM} \mathrm{Na} \triangleq 445 \mathrm{mOsm} \mathrm{kg}{ }^{-1}\right)$. Data represent means, and vertical bars standard deviations, obtained from a sample size of 5 (gill 4) and 4 (gill 8) individuals 


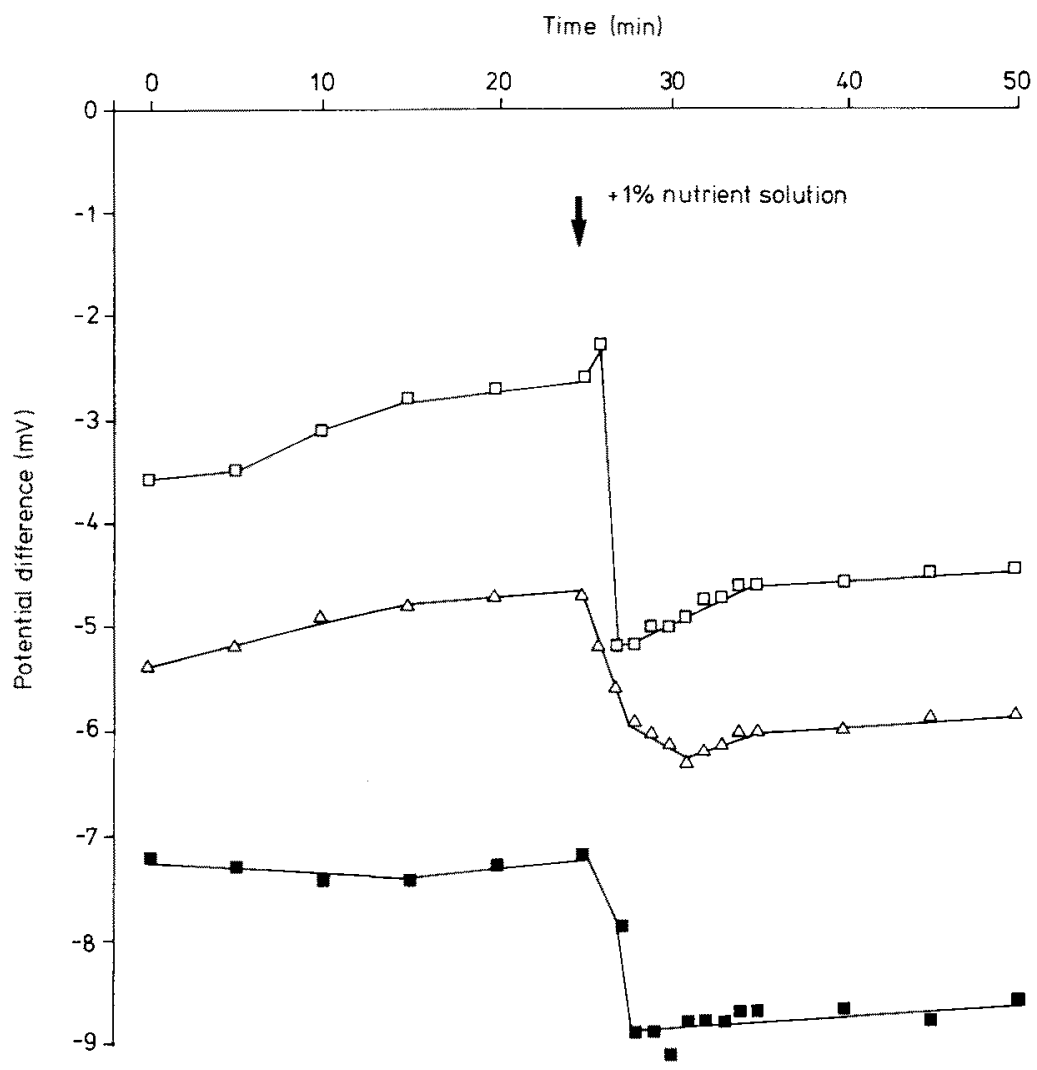

Fig. 3. Carcinus maenas. Effect of added nutrients on the PD. Potential differences across isolated perfused gills 8 of crabs acclimated to $10 \%$ S were established by bathing and perfusing the gills with $50 \%$ sea water. At the point indicated, $1 \%$ of an artificial nutrient solution $\left(\mathrm{NH}_{4} \mathrm{Cl} 100 \mathrm{mM}_{\text {, }}\right.$ glucose $100 \mathrm{mM}$, glycine $30 \mathrm{mM}$, proline $20 \mathrm{mM}$, taurine $20 \mathrm{mM}$, lysine $20 \mathrm{mM}$ ) was added symmetrically on both sides

\section{Effect of nutrients on the potential difference}

Potential differences across isolated perfused gills 8 of $C$. maenas acclimated to $10 \% \mathrm{~S}$ were measured in controls (bathing and perfusing the gills with $50 \%$ sea water). As shown in Figure 3 , the transepithelial PD remained relatively constant but was stabilized to more negative values by symmetrical addition of $1 \%$ of a nutrient solution. Further enhancement of nutrients had no effect. The nutrient solution was composed according to the hemolymph concentration of the six most frequent substances (amino acids and glucose) in C. maenas (Siebers et al., 1972). The results obtained indicate that the isolated gill organ can generate potential differences of active nature, utilizing its own sources of energy or by additional use of externally available nutrients. 
The active nature of the potential difference

In order to obtain stable, potential differences the following experiments were performed with $50 \%$ natural sea water (including $1 \%$ artificial nutrient solution) employed symmetrically as bathing and perfusing medium. The PD measured under these control conditions was abolished by the addition of $5 \cdot 10^{-3} \mathrm{M}$ sodium cyanide to the external medium within a few minutes (Fig. 4). Inhibition by $\mathrm{NaCN}$ was affected in a concentration dependent mode (Fig. 5: Table 1). A concentration of $10 \mu \mathrm{M} \mathrm{NaCN}$ applied to the external and internal medium seemed to be without effects on PD. Increase of the sodium cyanide concentrations applied resulted in stepwise reductions of PD values until new steady-state PDs were reached. Concentrations of $\mathrm{NaCN}$ between 150 and 500 $\mu \mathrm{M}$ up to $5 \mathrm{mM}$ resulted in a total breakdown of the PD in isolated perfused gills of $C$. maenas (Table 1).

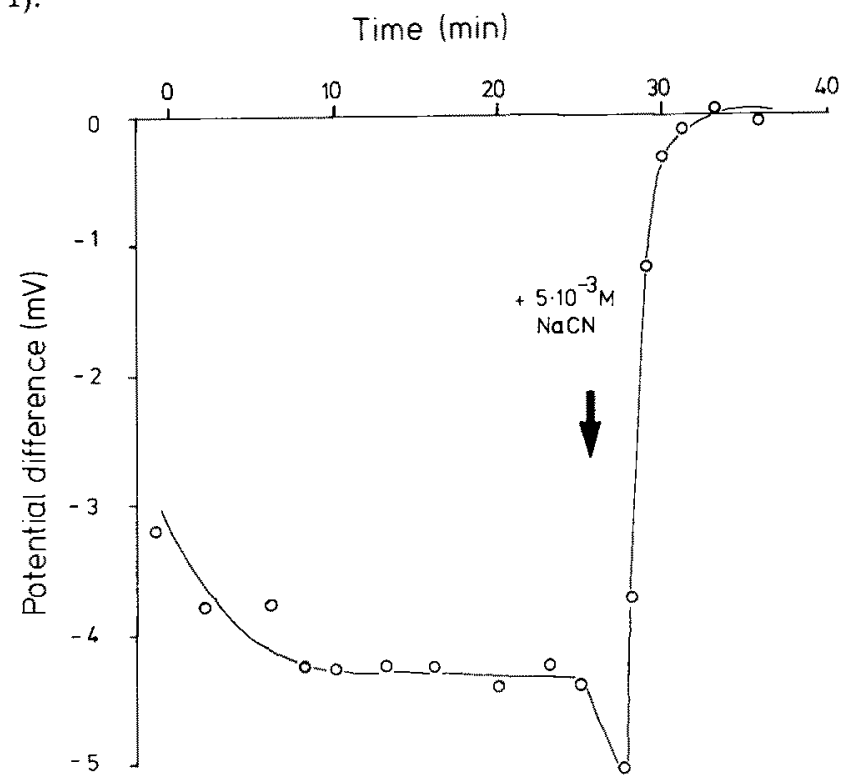

Fig. 4. Carcinus maenas. Addition of $5 \cdot 10^{-3} \mathrm{M}$ sodium cyanide to the bathing medium of an isolated perfused gill 8 of a crab acclimated to $10 \% \mathrm{~S}$ resulted in breakdown of the PD within a few minutes. Bathing and perfusion medium were $50 \%$ sea water including $1 \%$ artificial nutrient solution

In addition to the experiments with $\mathrm{NaCN}$ the same effects were studied with 2,4dinitrophenole (DNP). Addition of $0.5 \cdot 10^{-3} \mathrm{M} 2,4$-DNP to the external medium resulted in complete breakdown of the potential difference within a few minutes (Fig. 6). Inhibition of the PD by 2,4-DNP was also concentration dependent (Fig. 7, Table 2). A concentration of $20 \mu \mathrm{M} 2,4-\mathrm{DNP}$, applied symmetrically in external and internal medium, was nearly without effects. Concentrations of 2,4-DNP between 50 and $300 \mu \mathrm{M}$ resulted in stepwise reductions of PD values. Total breakdown of the potential differences was achieved with $500 \mu \mathrm{M} 2$,4-DNP in external and internal medium (Table 2). Reestablishment of PDs reduced as a consequence of 2,4-DNP application is shown in Figure 8. The findings indicate that the control PD was abolished by addition of 2,4-DNP 


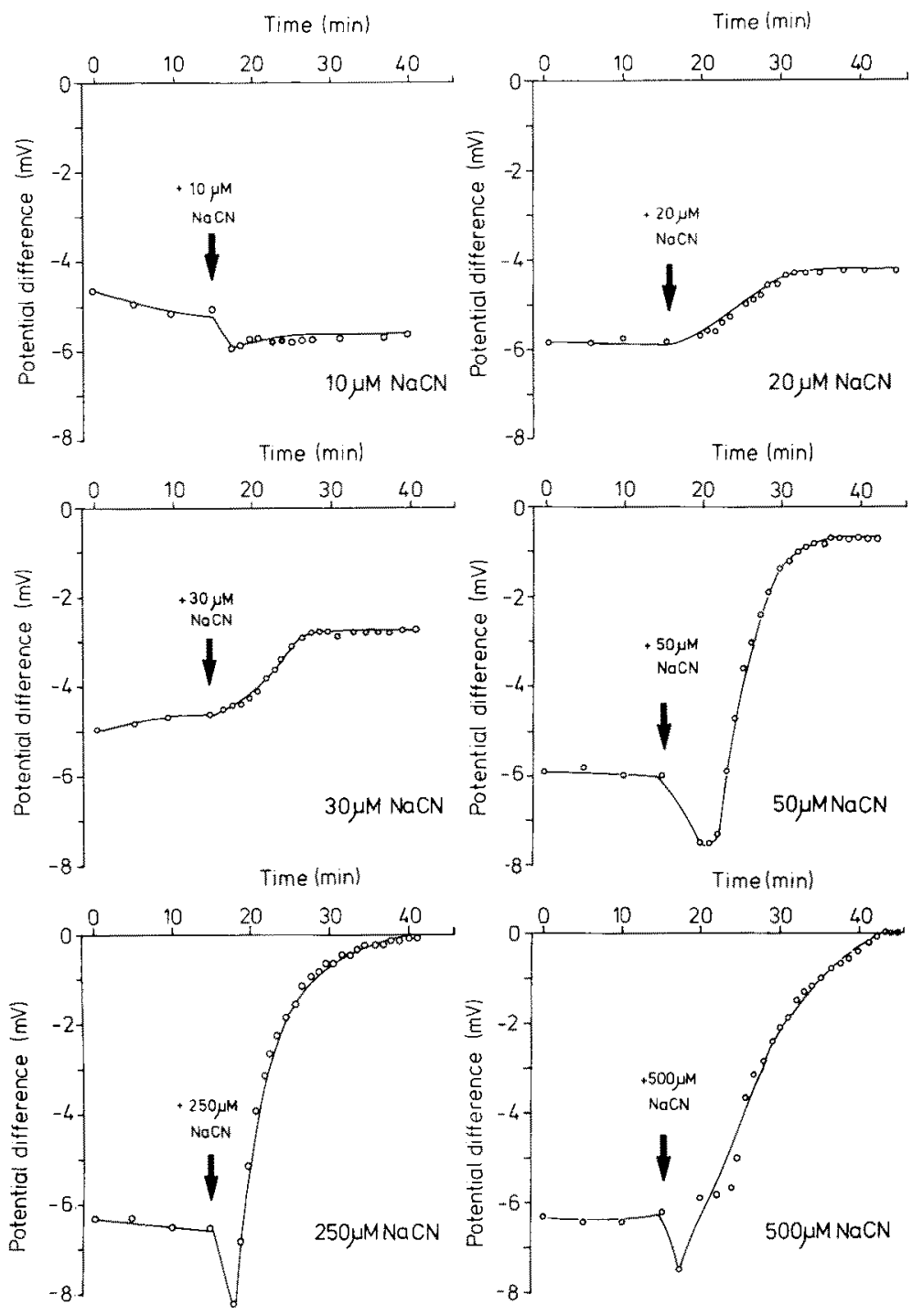

Fig. 5. Carcinus maenas. Concentration-dependent inhibition of potential differences in isolated perfused gills 8 of crabs acclimated to $10 \% \mathrm{~S}$ by NaCN. At the points indicated NaCN was applied in the external and internal medium. Bathing and perfusion medium were $50 \%$ sea water including $1 \%$ artificial nutrient solution

to both external and internal medium. At the points indicated, bathing and perfusion medium were exchanged against $50 \%$ sea water free of 2,4-DNP. Potential differences could be restored again to negative values of -4 to $-6 \mathrm{mV}$. This was possible even in the experiment where the PD was completely reduced by $500 \mu \mathrm{M}$ DNP, but the reestablished PD did not reach the level of the unaffected controls. 


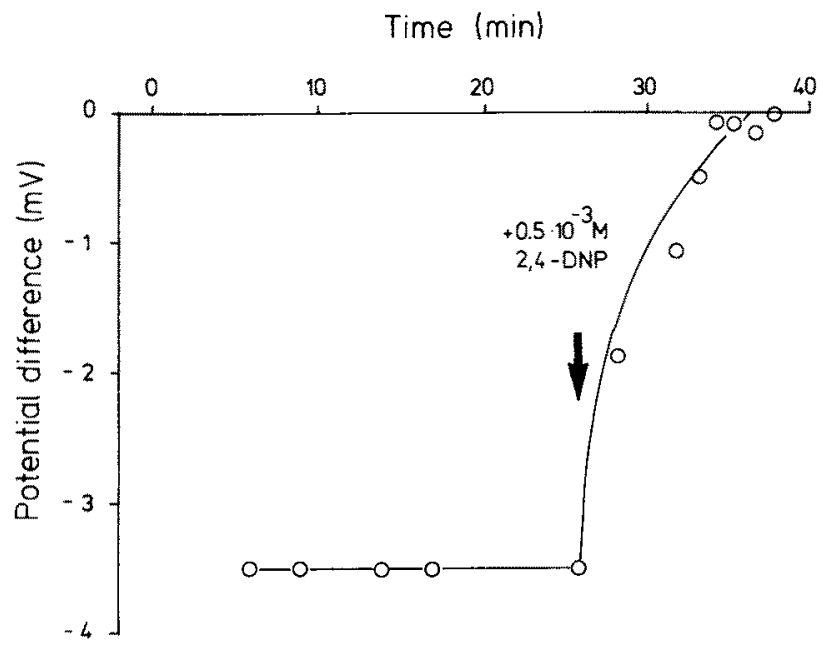

Fig. 6. Carcinus maenas. Addition of $0.5 \cdot 10^{-3} \mathrm{M} 2,4$-dinitrophenole to the bathing medium of an isolated perfused gill 8 of a crab acclimated to $10 \% \mathrm{~S}$ resulted in breakdown of the PD within a few minutes. Bathing and perfusion medium were $50 \%$ sea water including $1 \%$ artificial nutrient solution

\section{Effects of triamterene on the transepithelial potential difference}

The diuretic drugs amiloride and triamterene are known to affect apical Na-entry in the gills of decapod crustaceans (Drews, 1985; Lucu \& Siebers, 1986). In addition to experiments with amiloride on Na-entry in the gills of C. mediterraneus (Lucu \& Siebers, 1986) and $C$. maenas (Siebers, personal communication) triamterene was employed in order to test whether or not Na-uptake in shore crabs is sensitive to this drug. In order to test the influence of triamterene on the establishment of the potential difference in $C$. maenas, the drug was added to bathing and perfusion salines. At a concentration of $10^{-6} \mathrm{M}$ no effect was observed. When $10^{-5} \mathrm{M}$ and $10^{-4} \mathrm{M}$ triamterene were added to the

Table 1. Carcinus maenas. Transepithelial potential differences (PD) of isolated perfused posterior gills in relation to the concentration of $\mathrm{NaCN}$ applied symmetrically in external and internal medium. Data represent means and standard deviations obtained from a sample size of 3-5 individuals

\begin{tabular}{|cccc|}
\hline $\begin{array}{c}\text { Concentration } \\
\text { of NaCN }(\mu \mathrm{M})\end{array}$ & $\begin{array}{c}\text { PD }(\mathrm{mV}) \\
\text { of controls }\end{array}$ & $\begin{array}{c}\text { Affected } \\
\mathrm{PD}(\mathrm{mV})\end{array}$ & $\begin{array}{c}\Delta \mathrm{PD} \\
(\mathrm{mV})\end{array}$ \\
\hline 10 & $-5.6 \pm 1.2$ & $-5.9 \pm 2.4$ & -0.3 \\
20 & $-6.0 \pm 1.3$ & $-4.4 \pm 1.5$ & 1.6 \\
30 & $-4.6 \pm 0.3$ & $-2.8 \pm 0.1$ & 1.8 \\
50 & $-5.5 \pm 1.8$ & $-3.2 \pm 2.3$ & 2.3 \\
100 & $-4.6 \pm 1.4$ & $-1.7 \pm 0.5$ & 2.9 \\
150 & $-3.1 \pm 0.2$ & $+0.4 \pm 0.8$ & 3.5 \\
250 & $-4.8 \pm 1.5$ & $+0.2 \pm 0.9$ & 5.0 \\
500 & $-5.5 \pm 1.0$ & $0.0 \pm 0.1$ & 5.5 \\
\hline
\end{tabular}




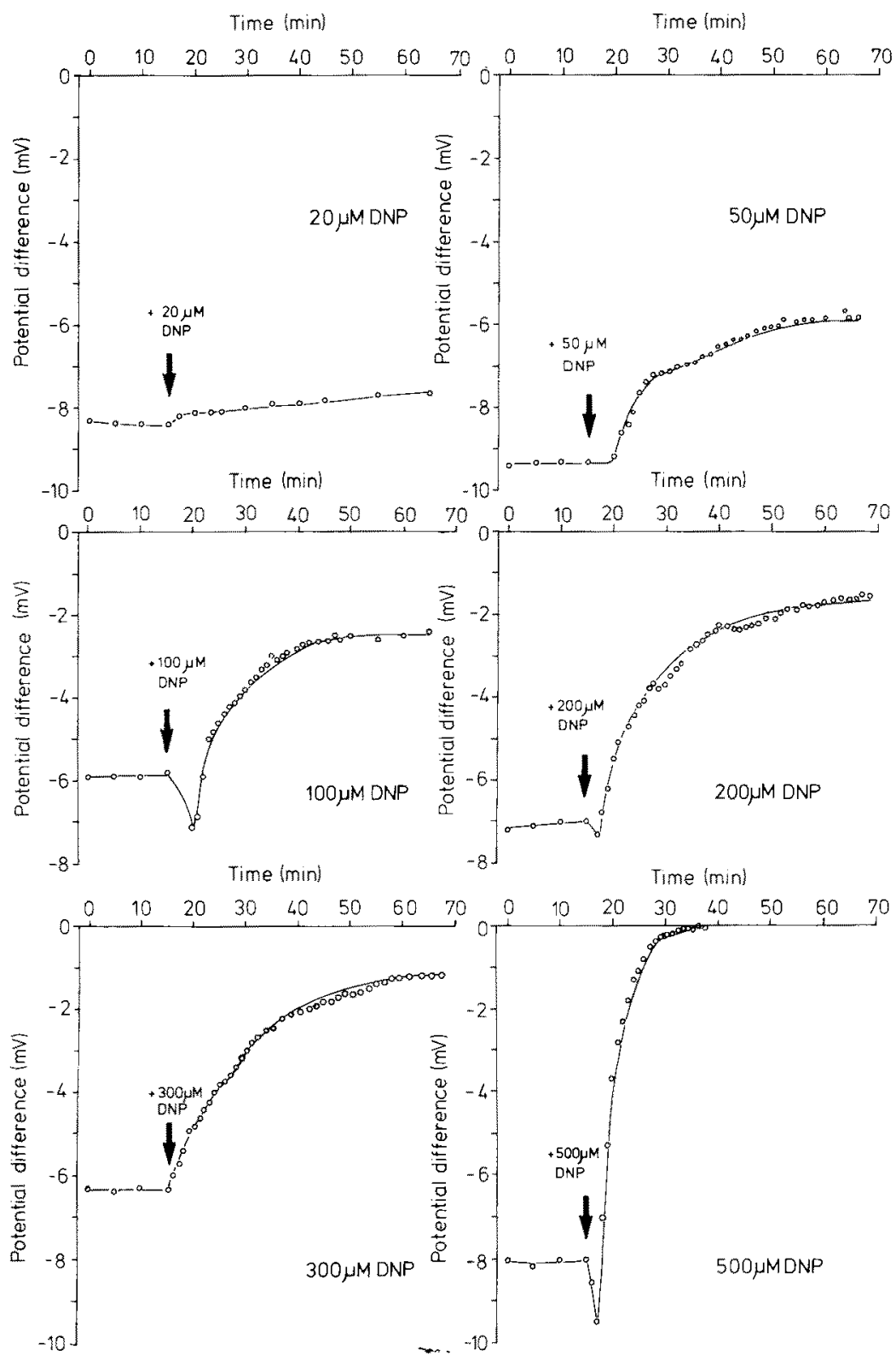

Fig. 7. Carcinus maenas. Concentration-dependent inhibition of potential differences in isolated perfused gills 8 of crabs acclimated to $10 \%$ S by 2,4 -DNP. At the points indicated, DNP was applied in the external and internal medium. Bathing and perfusion medium were $50 \%$ sea water including $1 \%$ artificial nutrient solution 
Table 2. Carcinus maenas. Transepithelial potential differences (PD) of isolated perfused posterior gills in relation to the concentration of DNP applied symmetrically in external and internal medium.

Data represent means and standard deviations obtained from a sample size of 3 individuals

\begin{tabular}{|cccc|}
\hline $\begin{array}{c}\text { Concentration } \\
\text { of DNP }(\mu \mathrm{M})\end{array}$ & $\begin{array}{c}\text { PD }(\mathrm{mV}) \\
\text { of controls }\end{array}$ & $\begin{array}{c}\text { Affected } \\
\mathrm{PD}(\mathrm{mV})\end{array}$ & $\begin{array}{c}\Delta \mathrm{PD} \\
(\mathrm{mV})\end{array}$ \\
\hline 20 & $-6.2 \pm 2.2$ & $-5.7 \pm 2.1$ & 0.5 \\
50 & $-7.6 \pm 1.6$ & $-5.1 \pm 0.5$ & 2.5 \\
100 & $-6.2 \pm 1.2$ & $-3.1 \pm 0.8$ & 3.1 \\
200 & $-5.9 \pm 1.1$ & $-1.9 \pm 0.5$ & 4.0 \\
300 & $-6.4 \pm 0.1$ & $-1.8 \pm 0.8$ & 4.6 \\
500 & $-5.0 \pm 2.6$ & $-0.1 \pm 0.1$ & 4.9 \\
\hline
\end{tabular}

external medium, concentration dependence became obvious (Figs 9-11). When under control conditions constant potential differences had been established, triamterene was added to the external medium, resulting in more negative PDs. Triamterene effects were reversible irrespective of the concentration applied. PDs decreased following triamterene treatment, re-increased to original control levels when the drug was omitted (Figs $9,10)$. Addition of $10^{-5}$ and $10^{-4} \mathrm{M}$ triamterene to the internal perfusion medium was without effect on the potential difference.

\section{DISCUSSION}

\section{Whole body potentials}

Whole body potential differences measured between hemocoel of Carcinus maenas and external medium in relation to acclimation salinity did not differ significantly. Using shore crabs $C$. maenas acclimated to various external salinities, Greenaway (1976) and Zanders (1980) determined whole body potential differences. They found PDs of approx. $-1 \mathrm{mV}$, which were independent of acclimation salinity. Zanders (1980) concluded that the small size of the PD in dilute media reflected the low ion selectivity of the surfaces involved in the exchanges between crabs and medium.

In contrast to whole body PDs, results obtained from isolated, perfused gills seem to be better suited to demonstrate the relation between $P D$ and active ion uptake. It is shown in the present work that relatively large negative PDs of similar millivolts can be measured between blood and medium. They suggestedly (Siebers et al., 1985, 1986) represent the driving force for active Na uptake. In addition, these PDs depend on the salinity of the incubation medium. The data presented consequently suggest that whole body PDs do not represent the electrical situation as at the gill, which is responsible for active ion transport.

Potential differences between whole crabs and the acclimation media were surely the results of various transport processes occurring not only via epithelial cells of the gills but also between other organs (digestive gland, antennal gland, etc.). Changes in uptake rates at the branchial level with respect to ambient salinity might be compensated for and thus removed from experimental detection. 


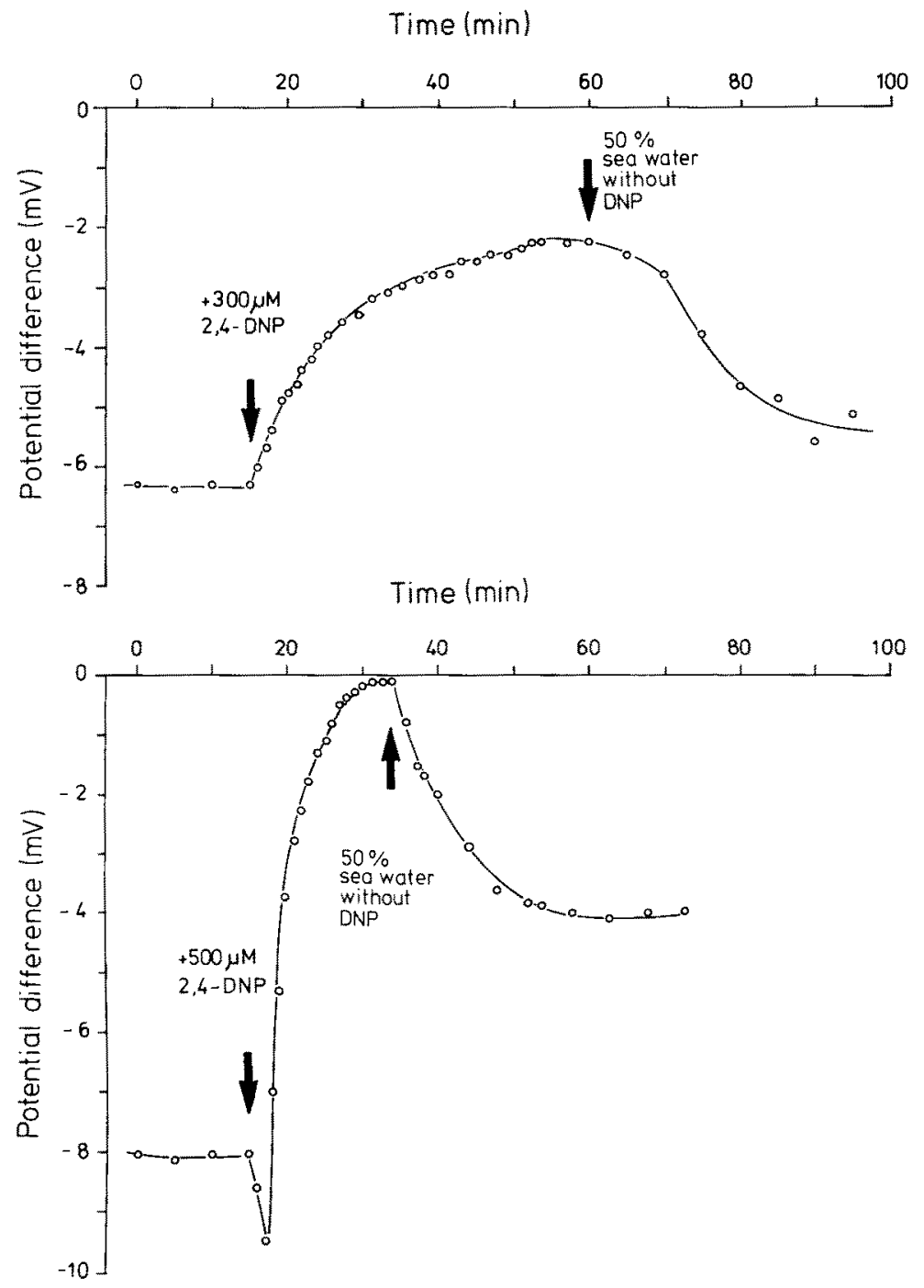

Fig. 8. Carcinus maenas. Potential differences in isolated perfused gills 8 of crabs acclimated to $10 \% \mathrm{~S}$ in absence and in the presence of 2,4-dinitrophenole. Bathing and perfusing medium were $50 \%$ sea water including $1 \%$ artificial nutrient solution

\section{The role of the Na-K-ATPase}

The technique of perfusing isolated crab gills has been used by various authors (Habas Mantel, 1967; King \& Schoffeniels, 1969; Berlind \& Kamemoto, 1977; Péqueux \& Gilles, 1978, 1981; Burnett, 1984). Most of them applied asymmetrical conditions, using bathing media with lower salt concentrations compared to perfusion media, and therefore mainly measured diffusional potentials. Consequently, the comparatively small 
active components that are measurable only under symmetrical conditions were overlooked. When isolated crab gills were - as in the present experiments - bathed and perfused with the same solution symmetrically on both sides, a spontaneous transepithelial potential difference between bath side (external medium) and blood side (internal medium) was established (Drews, 1985; Siebers et al., 1985, 1986).

It was suggested by the work of Siebers et al. (1985) that the Na-K-ATPase is responsible for the establishment of the transepithelial potential difference at the gill level.

In the present study further evidence in this respect is given. Siebers et al. (1982) investigated the Na-K-ATPase activity in the gills of C. maenas and showed that enzyme

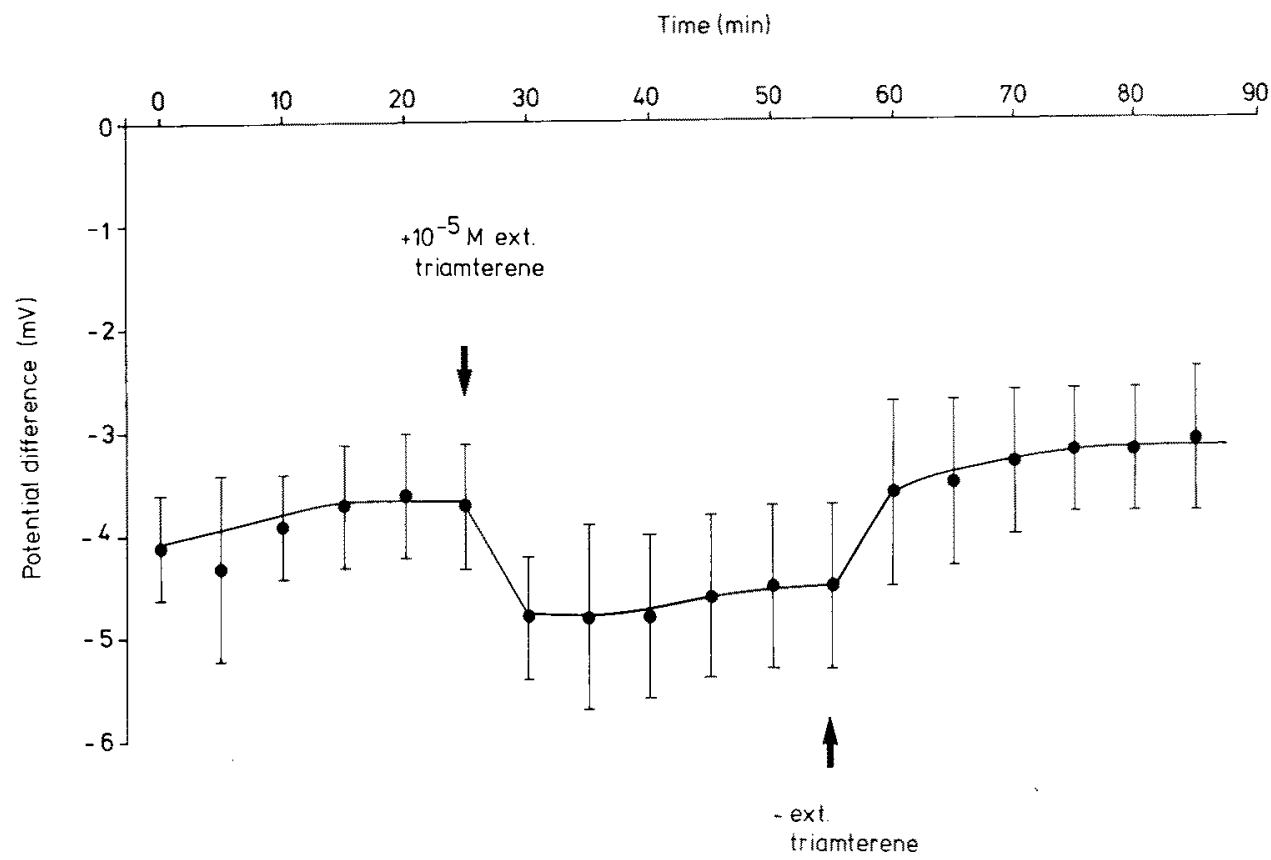

Fig. 9. Carcinus maenas. Effects of $10^{-5} \mathrm{M}$ external triamterene on the potential differences across isolated perfused gills 8 of crabs acclimated to $10 \% \mathrm{~S}$. Bathing and perfusing medium were $50 \%$ sea water. Data represent means, and vertical bars standard deviations, obtained from a sample size of 6 individuals

activities were highest in posterior gills (7-9), in contrast to anterior gills (1-6) displaying $50-70 \%$ lower activity levels. In C. maenas, PD levels were more negative in posterior gills than in anterior gills of the same individuals (Fig. 2). This finding seems to correlate with the different amounts of enzyme molecules present in anterior and posterior gills. These results closely correspond to the data found by Drews (1985) working with fiddler crabs Uca tangeri. In the chinese crab Eriocheir sinensis, the PD measured in absence of a concentration gradient across the epithelium was negative in posterior and positive in anterior gills (Péqueux \& Gilles, 1978). Different PDs in anterior and posterior gills thus correspond closely to the differences in Na-K-ATPase levels. 


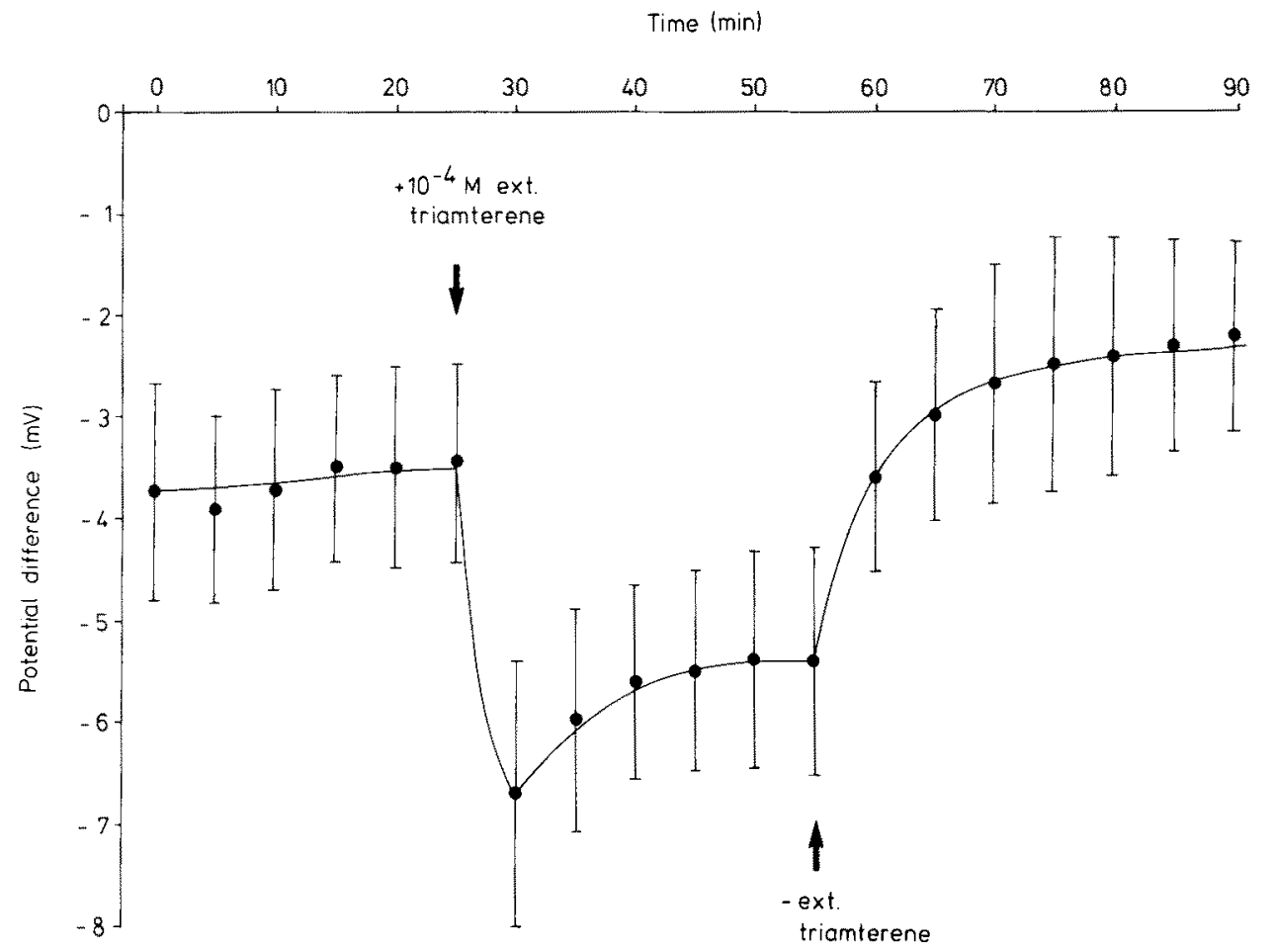

Fig. 10. Carcinus maenas. Effects of $10^{-4} \mathrm{M}$ external triamterene on the potential differences across isolated perfused gills 8 of crabs acclimated to $10 \% \mathrm{~S}$. Bathing and perfusion medium were $50 \%$ sea water. Data represent means, and vertical bars standard deviations, obtained from a sample size of 7 individuals

Concentration of ext. triamterene (M)
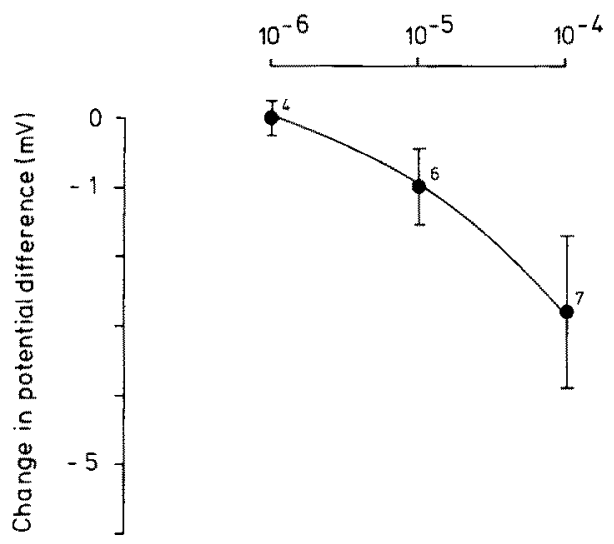

Fig. 11. Carcinus maenas. Changes in potential differences in isolated perfused gills 8 of crabs acclimated to $10 \% \mathrm{~S}$ in relation to the concentration of external triamterene. Bathing and perfusion medium were $50 \%$ sea water. Data represent means, and vertical bars standard deviations. The number of individuals is shown besides the means 


\section{Effects of $\mathrm{NaCN}$ and dinitrophenole}

The results shown in Figures 4-7 indicate that the PD is of active nature and requires the metabolism of the living cell. Non-availibility of biological energy following application of cyanide and 2,4-DNP resulted in breakdown of the PD. Cyanide ions act as blockers of the respiratory chain. The electron flow is stopped at the point of cytochrome oxidase by inhibition of the component $a_{3}$. Dinitrophenole is known to be an uncoupling agent of the oxidative phosphorylation which completely suppresses the formation of ATP in mitochondria while the oxidation of substrate continues. When 2,4-DNP was omitted during the experiment the potential difference was re-established (Fig. 8) surely as a result of available ATP. Working in the same manner as described in the present paper, Drews (1985) abolished the PD in isolated perfused gills of the fiddler crab, Uca tangeri, by addition of $10^{-3} \mathrm{M} \mathrm{KCN}$ and $10^{-3} \mathrm{M} \mathrm{DNP}$ to the internal medium. Addition to the external medium was less effective. Reversible inhibition of active transport processes had been observed by Koch et al. (1954) in isolated gills of the chinese crab, Eriocheir sinensis, when low concentrations of $\mathrm{KCN}, \mathrm{NaN}_{3}$, and $\mathrm{Na}_{2} \mathrm{~S}$ were present in the incubation medium. In the blue crab, Callinectes sapidus, $10^{-4} \mathrm{M}$ DNP caused a reduction of gill potentials (Habas Mantel, 1967). Péqueux \& Gilles (1978) measured an irreversible fall in PD occurring when DNP was added to perfusion or incubation media in experiments with excised gills of E. sinensis. Finally, Siebers et al. (1986) recorded a steady reduction of the PD towards zero levels in a $9 \mathrm{~h}$ lasting experiment when $50 \%$ sea water without additional nutrients was used as bathing and perfusion medium. Exhaustion of energy reserves was regarded as responsible for the decrease of active sodium influx to passive efflux levels in isolated perfused gills of C. maenas.

\section{Effects of triamterene on the transepithelial potential difference}

Amiloride and triamterene are known to act at low concentrations $\left(10^{-7}-10^{-6} \mathrm{M}\right)$ on passive $\mathrm{Na}^{+}$-entry through channels at the apical cell surface of tight epithelia. At higher concentrations $\left(10^{-5}-10^{-3} \mathrm{M}\right.$ ), the drugs affect the apical $\mathrm{Na}^{+} / \mathrm{H}^{+}$-exchanger (for further references see Benos et al., 1979; Kinsella \& Aronson, 1981).

The findings of amiloride effects (Lucu \& Siebers, 1986) and the data presented in this work on triamterene indicate that the gill of the shore crab is comparable with other ion-transporting epithelia when considering the susceptibility of the apical membrane to the diuretic drugs. Triamterene (present paper) and amiloride (Lucu \& Siebers, 1986) decrease the control potential differences to still more negative values. This change in PD has also been observed by Drews (1985) using posterior gills of Uca tangeri. Her assumption that the change of $P D$ to still more negative internal values results from inhibited entry of $\mathrm{Na}^{+}$, while $\mathrm{Cl}^{-}$-fluxes still proceed, has been confirmed by direct measurements of $\mathrm{Na}^{+}$- and $\mathrm{Cl}^{-}$-fluxes in Carcinus mediterraneus by Lucu \& Siebers (1986). UCa and Carcinus (Fig. 11) are both less sensitive to triamterene when compared to amiloride. In conclusion, the results of this work suggest that active uptake of sodium from medium to blood across the gills is performed by a complex mechanism including participation of several basal (Na-K-ATPase) and apical $\left(\mathrm{Na}^{+}\right.$-channels and/or $\mathrm{Na}^{+} / \mathrm{H}^{+}$exchanger) transport steps.

Acknowledgements. I wish to thank Prof. Dr. W. Becker, Zoologisches Institut und Museum, University of Hamburg, and Dr. D. Siebers, Biologische Anstalt Helgoland, for helpful discussions 
and critical reading of the manuscript. I am grateful to U. Grammerstorf, G. Thedens and $\mathrm{H}$. Wille for their technical assistance. This research is part of the programme "Stoffwechsel unter Extrembedingungen" of the Deutsche Forschungsgemeinschaft, whose grant (Si 295/1-4) is gratefully accepted. This article is based on a doctoral thesis submitted to the Faculty of Biology, University of Hamburg.

\section{LITERATURE CITED}

Benos, D. J., Mandel, L. J. \& Balaban, R. S., 1979. On the mechanism of the amiloride-sodium entry site interaction in anuran skin epithelia. - J. gen. Physiol. 73, 307-326.

Berlind, A. \& Kamemoto, F. I., 1977. Rapid water permeability changes in eyestalkless euryhaline crabs and in isolated, perfused gills. - Comp. Biochem. Physiol. 58A, 383-385.

Burnett, L. E., 1984, $\mathrm{CO}_{2}$-excretion across isolated perfused crab gills: Facilitation by carbonic anhydrase. - Am. Zool. 24, 253-264.

Drews, $G$., 1985. Elektrophysiologische und biochemische Untersuchungen zur osmoregulatorischen Fähigkeit und zur Salzaufnahme über das Kiemenepithel von Uca tangeri. Diss., Freie Univ. Berlin, 139 pp.

Greenaway, P., 1976. The regulation of haemolymph calcium concentration of the crab Carcinus maenas (L.). - J. exp. Biol. 64, 149-157.

Habas Mantel, L., 1967. Asymmetry potentials, metabolism and sodium fluxes in gills of the blue crab Callinectes sapidus. - Comp. Biochem. Physiol. 20, 743-753.

King, E. N. \& Schoffeniels, E., 1969. In vitro preparation of crab gill for use in ion transport studies.Archs int. Physiol. Biochim. 77, 105-111.

Kinsella, J. L. \& Aronson, P. S., 1981. Amiloride inhibition of the $\mathrm{Na}^{+}-\mathrm{H}^{+}$exchanger in renal microvillus membrane vesicles. - Am. J. Physiol. 241, F 374-F 379.

Koch, H. J., Evans, J. \& Schicks, E., 1954. The active absorption of ions by the isolated gills of the crab Eriocheir sinensis (M. Edw.). - Meded. vlaam. Acad. Kl. Wet. 16, 1-16.

Lucu, C. \& Siebers, D., 1986. Amiloride sensitive Na-flux and potentials in perfused Carcinus gill preparations. - J. exp. Biol. 122, 25-35.

Péqueux, A. \& Gilles, R., 1978. Osmoregulation of the euryhaline chinese crab Eriocheir sinensis. lonic transports across isolated perfused gills as related to the salinity of the environment. In: Physiology and behaviour of marine organisms. Ed. by D. S. McLusky \& A. J. Berry. Pergamon Press, Oxford, 105-111.

Péqueux, A. \& Gilles, R., 1981. $\mathrm{Na}^{+}$fluxes across isolated perfused gills of the chinese crab Eriocheir sinensis. - J. exp. Biol. 92, 173-186.

Siebers, D., Lucu, C., Sperling, K. R. \& Eberlein, K., 1972. Kinetics of osmoregulation in the crab Carcinus maenas. - Mar. Biol. 17, 291-303.

Siebers, D., Leweck, K., Markus, H. \& Winkler, A., 1982. Sodium regulation in the shore crab Carcinus maenas as related to ambient salinity. - Mar. Biol. 69, 37-43.

Siebers, D., Winkler, A., Lucu, C., Thedens, G. \& Weichart, D., 1985. Na-K-ATPase generates an active transport potential in the gills of the hyperregulating shore crab Carcinus maenas. - Mar. Biol. 87, 185-192.

Siebers, D., Lucu, C., Winkler, A., Dalla Venezia, L. \& Wille, H., 1986. Active uptake of sodium on the gills of the hyperregulating shore crab Carcinus maenas. - Helgoländer Meeresunters. 40, 151-160.

Towle, D. W., 1981. Role of the $\mathrm{Na}^{+}+\mathrm{K}^{+}$-ATPase in ionic regulation by marine and estuarine animals. - Mar. Biol. Lett. 2, 107-121.

Towle, D. W., 1984a. Regulatory functions of $\mathrm{Na}^{+}+\mathrm{K}^{+}$-ATPase in marine and estuarine animals. In: Osmoregulation in estuarine and marine animals. Ed. by A. Péqueux \& L. Bolis. Springer, Berlin, 157-170.

Towle, D. W., 1984b. Membrane-bound ATPases in arthropod ion-transporting tissues. - Am. Zool. $24,177-185$.

Winkler, A., Siebers, D. \& Leweck, K., 1982. Zur Bestimmung von Natrium im Meerwasser mit ionensensitiven Elektroden. - GIT Fachz. Lab. 26, 228-229.

Zanders, I. P., 1980. Regulation of blood ions in Carcinus maenas (L.). - Comp. Biochem. Physiol. $65 A, 97-108$. 